\title{
Descrição de uma nova espécie do gênero Cundinamarca Rindge (Lepidoptera, Geometridae) ${ }^{1}$
}

\section{Manoel Martins Dias ${ }^{2}$}

\begin{abstract}
Description of a new species of the genus Cundinamarca Rindge (Lepidoptera, Geometridae). The genus Cundinamarca Rindge, 1983 (Geometridae, Ennominae, Nacophorini) concerns four neotropical species. A fifth species from Brazil is now described: Cundinamarca beckeri sp. $\mathbf{n}$.

KEY WORDS. Lepidoptera, Geometridae, Ennominae, Nacophorini, Cundinamarca, new species
\end{abstract}

Cundinamarca Rindge, 1983 (Ennominae, Nacophorini) compreende quatro espécies neotropicais: C. indistincta (Warren, 1904), C. subalbata (Dognin, 1910), C. nigralbata (Dognin, 1913) e C. rindgei Dias, 1998. Uma nova espécie, C. beckeri, procedente do Brasil central, é ora acrescentada ao gênero; assemelha-se a $C$. rindgei pelas asas posteriores brancas, com faixa preta bem definida na margem externa, em ambas as faces.

\section{MATERIAL E MÉTODOS}

O material examinado pertence às coleções entomológicas citadas a seguir, acompanhadas dos nomes de seus responsáveis e das siglas correspondentes; estas são mencionas na relação do material.

Coleções examinadas: (BMNH) The Natural History Museum, London (M.J. Scoble); (VOBB) Coleção Vitor O. Becker, Brasília (V.O. Becker).

\section{Cundinamarca beckeri sp. $\mathbf{n}$.}

Figs 1-10

Macho. Asa anterior, margem costal: $16 \mathrm{~mm}$. Olhos grandes e salientes; fronte saliente, arredondada em vista anterior, com escamas castanhas e cinzento-oliváceas, dispostas em grupos irregulares. Vértice cinzento-oliváceo; palpos labiais idem, com escamas pretas dispersas. Antenas longas, bipectinadas; segmentos simples no terço apical; processos laterais castanho-claros, dilatados no ápice; segmentos da antena com escamas verde-oliváceas e castanhas, entremeadas; no terço apical, verde-oliváceas. Patágia e tégula verde-oliváceas, com escamas castanhas dispersas; tégula com escamas setiformes, castanhas, apicais. Tórax verde-oliváceo dorsalmente. Área posterior do mesonoto com tufo saliente de escamas, seguido de outros dois dispostos lado a lado; metanoto com banda transversal de escamas salientes. Áreas ventral e lateral do tórax, brancas, amareladas anteriormente. Pernas anteriores e medianas com

1) Realizado com auxilio do Programa BIOTA/FAPESP.

2) Departamento de Ecologia e Biologia Evolutiva, Universidade Federal de São Carlos. Caixa Postal 676, 13565-905 São Carlos, São Paulo, Brasil. 

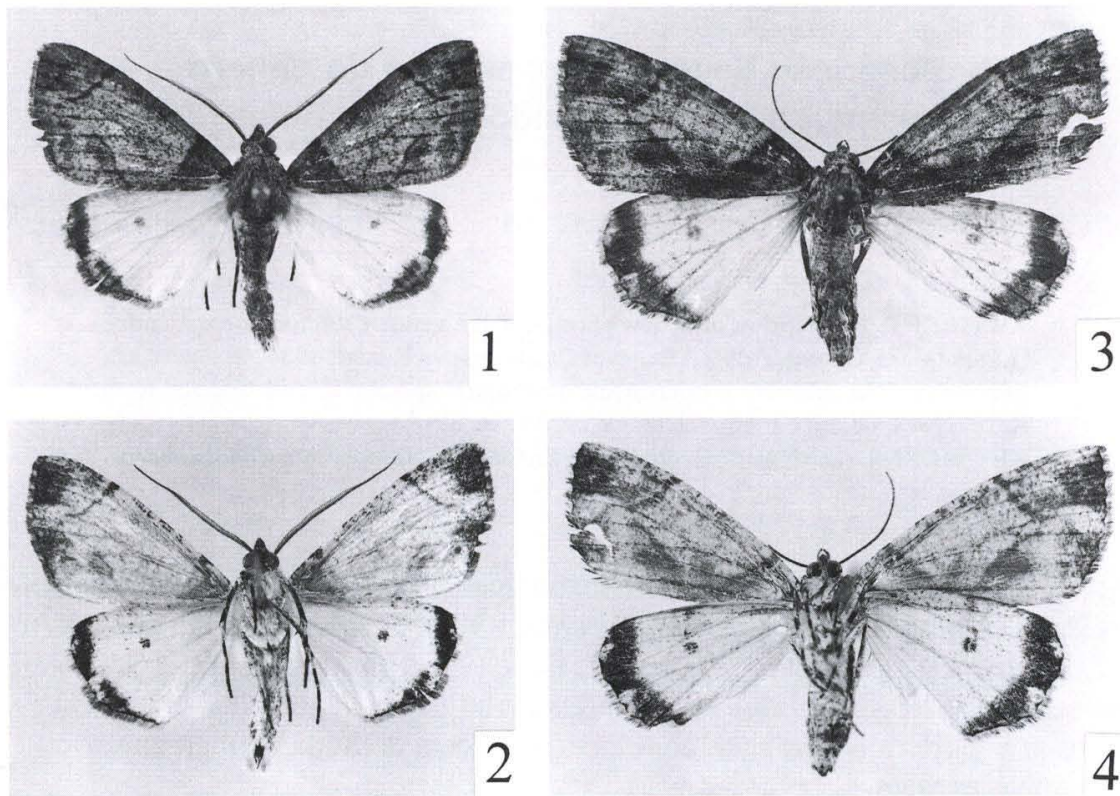

Figs 1-4. Cundinamarca beckerisp. n. (1) Holótipo macho, Alto Paraíso, Goiás; (2) idem, face inferior; (3) parátipo fêmea, Planaltina, Distrito Federal; (4) idem, face inferior.

fêmur branco, com manchas cinzentas; tíbia e tarsos com faixas transversais cinzentas. Pernas posteriores brancas, com manchas cinzentas; artículos tarsais apicais sobretudo pretos; tíbia dilatada, oblonga.

Abdome com área dorsal olivácea acinzentada, com escamas castanhas e pretas, dispersas; área ventral branca, com algumas escamas castanhas; cinco tufos dorsais de escamas cinzento-oliváceas, salientes, o maior no segmento 3 e o menor no segmento 6 .

Face superior da asa anterior cinzenta, com pontuação cinzenta-escura a preta, dispersa. Linha basal preta, reta, da margem costal à margem interna, delimita área basal triangular cinzenta-escura. Linha semelhante pós-discal, inicialmente paralela à primeira e depois curvada em ângulo abrupto em M3, dirigindo-se para dentro até atingir a margem interna; pouco aparente entre M3 e Cu2. Junto à linha pós-discal, mancha cinzenta-escura, alongada, próxima à margem interna; outras manchas da mesma cor junto à margem externa, a mais acentuada próxima ao ápice da asa.

Face superior da asa posterior sobretudo branca, com ponto cinzento, pouco aparente, no ápice da célula discal; margem costal com algumas escamas cinzentoclaras, formando apenas esboço de faixa marginal. Margem externa da asa posterior com faixa cinzenta-escura, ondulada e estreita, parcialmente ocupada por áreas claras, levemente róseas, externas; essa faixa é bem definida até $\mathrm{Cu} 2$, abaixo da qual é reduzida. 


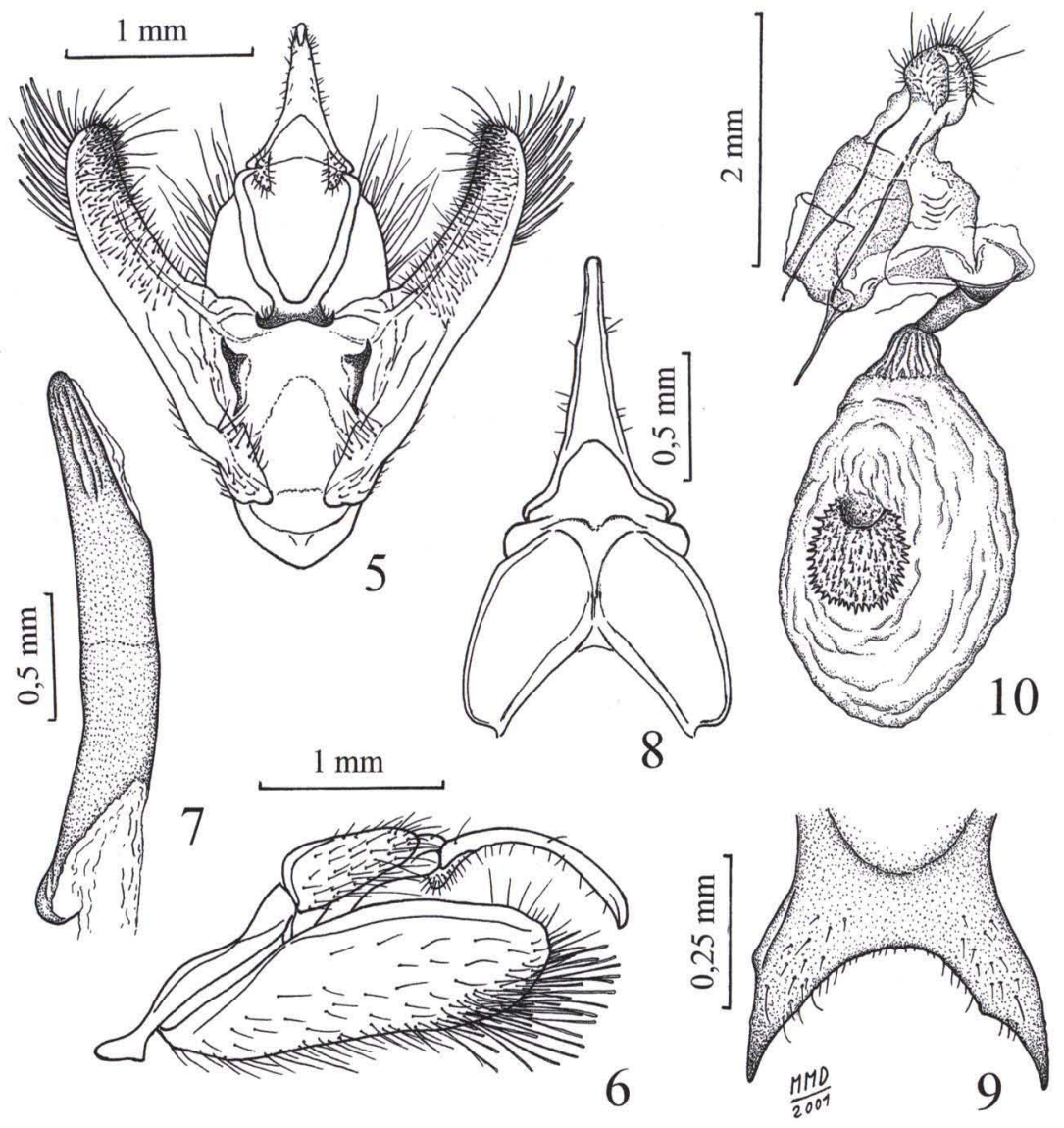

Figs 5-10. Cundinamarca beckeri sp. n. (5) Genitália masculina, vista ventral, edeago removido, holótipo, Alto Paraíso, Goiás; (6) idem, vista lateral; (7) idem, edeago; (8) idem, tegume e unco, vista dorsal; (9) idem, processo do gnato, vista posterior; (10) genitália feminina, vista látero-ventral, parátipo, Planaltina, Distrito Federal.

Face inferior das asas, branca com pontuação e manchas cinzento-escuras a pretas. Asa anterior com pontuação e manchas evidentes no ápice e margem externa; linha pós-discal reta, da margem costal à M3; margem costal com pequenas manchas pretas, a maior e mais evidente no início da linha pós-discal. Asa posterior com ponto preto, evidente, no ápice da célula discal; faixa marginal preta, semelhante àquela da face superior, interrompida por manchas brancas; algumas escamas cinzentas, dispersas, sobretudo na margem costal.

Genitália masculina (Figs 5-9). Difere daquela de Cundinamarca rindgei ilustrada em DIAS (1998) por: unco mais afilado e menos curvado para baixo; tegume mais estreito na base e com lados menos convergentes; processos do gnato mais afilados e estreitos na base; processos do anelo mais estreitos na base; face interna das valvas com cerdas concentradas no ápice e mais esparsas na metade distal da valva. 
Fêmea. Asa anterior, margem costal: 20-21 mm. Semelhante ao macho. Olhos menores e menos salientes. Antenas com segmentos simples. Pernas posteriores com tíbias menos dilatadas; estas, com escamas castanho-claras, dispersas, formando manchas irregulares.

Asas anteriores mais alongadas. Face superior das asas anteriores cinzentaacastanhada; linha basal preta bem definida ou alargada e difusa com área basal cinzenta-escura, triangular; mancha externa à linha pós-discal, cinzenta-escura ou preta; linha pós-discal aparente ou não entre M3 e CuA2.

Face superior das asas posteriores com faixa cinzenta-escura mais larga, na margem externa; com escamas cinzentas dispersas, pós-discais, mais concentradas junto à margem costal; próximo à célula discal, pontos pretos sobre $\mathrm{M} 3, \mathrm{CuA} 1 \mathrm{e}$ $\mathrm{CuA} 2$, presentes ou não.

Face inferior das asas mais pontuada que aquela do macho, com manchas cinzentas mais amplas; asa anterior acinzentada-clara, destacada da posterior, branca.

Genitália feminina (Fig. 10). Papilas anais arredondadas no ápice. Esterigma com lamela antevaginal esclerosada, transversal, alargada dos lados; lamela pós-vaginal membranosa. Duto da bolsa com parte junto ao óstio, esclerosada, seguida de outra com maior diâmetro, membranosa e com estrias longitudinais salientes, um pouco irregulares. Corpo da bolsa oblongo; signo amplo, arredondado, com projeções espinescentes formando estrias aproximadamente radiais e margens com espinhos irregulares; signo mais arredondado que aquele de $C$. rindgei.

Material examinado (1 macho e 2 fêmeas). BRASIL, Goiás: Alto Paraíso, 1400 m, V.O. Becker leg., no.98609, 1 a 6-XI-1996, holótipo macho (VOBB); Leopoldo Bulhões, R. Spitz leg., XI-1935, parátipo fêmea (BMNH); Distrito Federal: Planaltina, 1000 m, V. O. Becker leg., 9-XI-1975, parátipo fêmea (VOBB).

Etimologia. O nome da espécie homenageia Dr. Vitor O. Becker, renomado lepidopterólogo.

AGRADECIMENTOS. Aos pesquisadores mencionados na relação das coleções estudadas, pelo acesso ao material examinado.

\section{REFERÊNCIAS BIBLIOGRÁFICAS}

DiAs, M.M. 1998. Considerações taxonômicas sobre o gênero Cundinamarca Rindge (Lepidoptera, Geometridae) e descrição de uma nova espécie. Revta bras. Zool. 15 (4): 951-958.

Dognin, P. 1910. Hétérocères nouveaux de l' Amerique du Sud. Rennes, Fasc. 1, p. 1-46. . 1913. Hétérocères nouveaux de l'Amerique du Sud. Mém. Soc. ent. Belg. 22: 1-54.

RINDGE, F.H. 1983. A generic revision of the new world Nacophorini (Lepidoptera: Geometridae). Bull.

Amer. Mus. Nat. Hist. 175 (2): 147-262.

WARren, W. 1904. New American Thyrididae, Uraniidae and Geometridae. Novit. Zool. 11 (1): 1-173.

Recebido em 24.IV.2001; aceito em 22.II.2002. 